\title{
Barrier and Motivation to Exclusive Breast Feeding Amongst Mothers Accessing Care at the University of Abuja Teaching Hospital
}

\author{
Christie Omolola Adams*, Godwin Ewu, Victoria Ugwu, Ibrahim Shakirat, Esther Joseph \\ Global Health Network Research Club, University of Abuja Teaching Hospital, Abuja, Nigeria
}

Email address:

loladams28@gmail.com (C. O. Adams)

${ }^{*}$ Corresponding author

To cite this article:

Christie Omolola Adams, Godwin Ewu, Victoria Ugwu, Ibrahim Shakirat, Esther Joseph. Barrier and Motivation to Exclusive Breast Feeding Amongst Mothers Accessing Care at the University of Abuja Teaching Hospital. International Journal of Immunology.

Vol. 8, No. 4, 2020, pp. 70-77. doi: 10.11648/j.iji.20200804.12

Received: September 9, 2020; Accepted: September 2, 2020; Published: November 23, 2020

\begin{abstract}
This study was carried out to identify barriers and motivation for exclusive breastfeeding practice amongst mothers accessing care at the University of Abuja Teaching Hospital, ( UATH) - Abuja - Nigeria. The study was a crosssectional survey that utilized a structured questionnaire in the collation of quantitative data from 288 participants. The data and result showed that approximately $53.5 \%$ of the respondents reportedly do not have enough breast milk, $13.9 \%$ think that the breast milk will not be enough for their babies because of the size of their breast, $0.69 \%$ were the students with attendant challenges, $1.4 \%$ were career women, $1.7 \%$ said their difficulty was painful nipples, one person was afraid that the baby may refuse other feeds at a later age while one respondent said it was time-consuming. It is captivating to know that, the respondents' motivation based on whether exclusive breastfeeding is beneficial to baby and mother shows that $99.6 \%$ claimed that exclusive breastfeeding is beneficial, and contribute to the good well-being of the baby, while $98.2 \%$ declared that exclusive breastfeeding is beneficial to the nursing mother as well. The study evaluated the barriers, and motivations of the mother to tell the benefits of breast milk are natural and renewable food. Therefore, ensuring active support through an efficient health education/promotion as primary prevention in public health/clinical practice and establishing/sustaining the practices that are appropriate among mothers. Generally, the study showed some barriers to exclusive breastfeeding and their associated motivations among mothers.
\end{abstract}

Keywords: Barrier/Motivation, Exclusive Breast Feeding, Mothers, UATH

\section{Introduction}

An extensive body of research has confirmed that mothers and other caregivers require active support for establishing and sustaining appropriate breastfeeding practices. World Health Organization (WHO) and United Nations Children's Fund (UNICEF) launched the Baby-friendly Hospital Initiative in 1992, to strengthen maternity practices in supporting breastfeeding [1]. The findings suggest that early initiation of breastfeeding reduces neonatal, and early infant mortality both through increasing rates of exclusive breastfeeding and by additional mechanisms [2]. Recommendation that, both practices should be promoted by public health program and be used in models to estimate saving lives. According to WHO,
"Exclusive breastfeeding" is defined as no other food or drink, not even water, except for breast milk (including milk expressed or from a wet nurse) for 6 months of life, but allows the infant to receive ORS, drops, and syrups (vitamins, minerals, and medicines) [33]. Interestingly, most children progressively gain weight and grow quickly within the first few years of life. Though, in some cases, some children may not meet these expected standards of growth. And when this happens, it can be said that there are infants' malnutrition, growth retardation, and eventually failure to thrive. Many things can cause malnutrition, growth retardation, or failure to thrive and these include illnesses and eating problems. When the cause of the problem is identified, then the families especially the mother will need to be motivated in correcting malnutrition [28]. Usually, after birth, a 
child's brain grows as much in the first year as it will grow for the rest of a child's life. Hence, poor nutrition during this period may have lasting harmful effects on brain development. Children who fail to thrive due to retard growth usually don't meet the commensurate milestones as expected. There is a need to achieve the health-related Sustainable Development Goal (SDG) 3 by ensuring that this global goal is met, starting from the grass root [21]. Also, there is so much evidence confirming that breastfeeding presents short and long-term advantages for infants, mothers, and the global community. Breast milk contains all the essential nutrients which stimulate optimal physiological and psychological growth and development [3-6]. In the short term, the incidence of childhood infections among breastfed children, such as diarrhea, respiratory infection, and other common childhood illnesses, tends to be lower due to the immunoglobulins present in breast milk [5]. The incidence of childhood and the risk of leukemia, the risk of being overweight or obese are also reduced $[4,6]$. Breastfeeding has also been found to reduce health outcomes like malocclusion [7, 11]. For long-term benefits, otitis media in children up to the age of 2 years can be prevented by breastfeeding and in all breastfeeding is estimated to have saved the lives of more than 820,000 children under the age of $5[4,8]$. There is evidence that the bonding between infants and mothers could be increased by breastfeeding [8]. Benefits to the mothers arise as a result of oxytocin and prolactin release, reducing the risk of postpartum hemorrhage, in addition to promoting uterine involution $[9,10]$. It has also been substantiated that, breastfeeding reduces the mother's risk of certain illnesses, including ovarian cancer, type 2 diabetes, obesity, hypertension, heart disease, maternal depression, and mortality rate from breast cancer [1, 4, 9, 13-15] Longer periods of amenorrhea, which can lead to birth spacing, are associated with breastfeeding [12, 16]. Breastfeeding has also been found to help women restore their body shape after delivery [4]. Not only health outcomes, but improvements in gender equality (in the workplace), money-saving, and fulfilling the mother's potential are other obvious benefits [17, 18]. For worldwide benefits, breast milk is recognized as a natural and renewable food; and the ecological footprint of feeding infants is minimized [19]. Regarding global spending, breastfeeding can save US\$ 302 billion annually [19, 23]. Developmental delay results in loss of interest in their surroundings, avoid eye contact, and may not reach developmental milestones like sitting up, walking, and talking at the usual age. According to the United Nations sustainable development goal 3 (Good health and wellbeing) "We have made great progress against several leading causes of death and disease. Life expectancy has increased dramatically; infant and maternal mortality rates have declined. Good health is essential to sustainable development and the 2030 Agenda reflects the complexity and interconnectedness of the two [21]. It takes into account widening economic and social inequalities, rapid urbanization, threats to the climate and the environment, the continuing burden of HIV and other infectious diseases, and emerging challenges such as non-communicable diseases" $[19,22]$. The purpose of this research will cut across identifying various barriers, and the motivation that is associated with exclusive breastfeeding practice from mothers, ensuring active support by establishing and sustaining the practices that are appropriate among mothers who access care at the University of Abuja Teaching Hospital - FCT - Abuja. Also, the findings from this research will help in promoting $\mathrm{WHO}$ and UNICEF programs domesticate the programs and to ensure the goal of SDG 3 through efficient health education, and promotion as primary prevention in public health and clinical practice.

\section{Methods}

\subsection{Study Setting}

The study was undertaken in two Departments of the University of Abuja Teaching Hospital, Gwagwalada, Abuja, North Central Nigeria, namely the Post Natal Outpatient Unit (Department of Obstetrics and Gynecology) and National Program on Immunization (NPI) Unit (Department of Community Health Medicine)

\subsection{Data Collection Methods}

This is a descriptive cross-sectional study and clients were selected by a systematic random sampling method. The data collection tool was an open-ended quantitative questionnaire with two domains that speak to barriers and motivations of mothers as they visit the clinics during puerperium. The interviews were carried out by one trained data collector. And data collection took place from February 2020 - August 2020. Inclusion criteria were mothers aged 20 to 40 years, who had children aged between 0 - 6 months, and mothers who are currently breastfeeding. While the exclusion criteria were mothers who were very ill e.g. eclampsia, mental health derangement, mothers who were unconscious, and children who were also very ill.

\subsection{Study Participants}

Study participants were recruited from a high patient load unit. The minimum sample size for the number of patients who were interviewed was calculated using the Leslie and Kish formula for descriptive studies $(\mathrm{Z} 2 \mathrm{pq} / \mathrm{d} 2$ where $\mathrm{z}=1.96$ ) [23]. There were 288 mothers in all.

\subsection{Ethical Considerations}

Ethical approval for the study was obtained from the Research Ethical Committee of the University of Abuja Teaching Hospital, Gwagwalada - Abuja.

Each participant gave their informed consent before participating in the study, and their anonymity, privacy, and confidentiality was respected. Consent was signed and obtained after reading and understanding the content of the consent form.

\subsection{Data Management and Analysis}

This deals mainly with the presentation and analysis of data collected from the respondents. The main purpose of this study was to investigate the barrier and motivation to Exclusive Breast Feeding (EBF) amongst mothers accessing care at the University of Abuja Teaching Hospital. Descriptive data analysis was done and the information 
collected was statistically presented through the use of percentages and graphs. Data from the questionnaire was cleaned, coded, and fed into Statistical Package for Social Sciences (SPSS) soft-ware 21 Version, for analysis. Microsoft Excel spreadsheet was used to provide means, frequency, and drawing various charts.

\section{Results}

\subsection{Socio-demographic Characteristics of Respondents}

Figure 1, shows the summary distribution of the respondents by age, marital status, educational qualification, and Employment status. The information on the table indicates that $36(12.5 \%)$ of the respondents were between 20 and 25 years of age, $75(26.04 \%)$ were between the age range of 26-30 years old, $151(52.43 \%)$ were in the age range of 31-35 years old, $26(9.03 \%)$ were between the age range of $36-40$ years old. The result further reveals that $262(90.97 \%)$ of the respondents were married, while 26 (9.03\%) were single mothers.

The table also indicates that $24(8.33 \%)$ of the respondents had no education, $56(19.44 \%)$ had primary school certificate, up to $79(27.43 \%)$ of the respondents had secondary school certificate while 129 (44.79\%) of the respondents had higher degrees. The table further depicts that 75 (26.04\%) of the respondents were full-time housewife, 108 (37.5\%) were self-employed, $86(29.86 \%)$ of the respondents were government workers while $19(6.6 \%)$ work at the private organization. Regarding the faith of the respondents, 131 which accounted for $45.5 \%$ of respondents were Christian, $156(54.2 \%)$ were Muslim and only one respondent claimed other religion which was not specified.

Table 1. Socio-demographic characteristics.

\begin{tabular}{|c|c|c|}
\hline Demographic Data & Frequency & Percentage (\%) \\
\hline \multicolumn{3}{|l|}{ Age } \\
\hline 20- 25 years old & 36 & 12.5 \\
\hline $26-30$ years old & 75 & 26.04 \\
\hline $31-35$ years old & 151 & 52.43 \\
\hline $36-40$ years old & 26 & 9.03 \\
\hline Total & 288 & 100.0 \\
\hline \multicolumn{3}{|l|}{ Marital status } \\
\hline Single mother & 26 & 9.03 \\
\hline Married & 262 & 90.97 \\
\hline Total & 288 & 100.0 \\
\hline \multicolumn{3}{|l|}{ Educational Qualification } \\
\hline No Education & 24 & 8.33 \\
\hline Primary & 56 & 19.44 \\
\hline Secondary & 79 & 27.43 \\
\hline Tertiary & 129 & 44.79 \\
\hline Total & 288 & 100.0 \\
\hline \multicolumn{3}{|l|}{ Employment status } \\
\hline Housewife & 75 & 26.04 \\
\hline Self-employed & 108 & 37.5 \\
\hline Government Employee & 86 & 29.86 \\
\hline Private Employee & 19 & 6.6 \\
\hline Total & 288 & 100.0 \\
\hline \multicolumn{3}{|l|}{ Religion } \\
\hline Christianity & 131 & 45.49 \\
\hline Islam & 156 & 54.17 \\
\hline Other & 1 & 0.35 \\
\hline Total & 288 & 100.0 \\
\hline
\end{tabular}

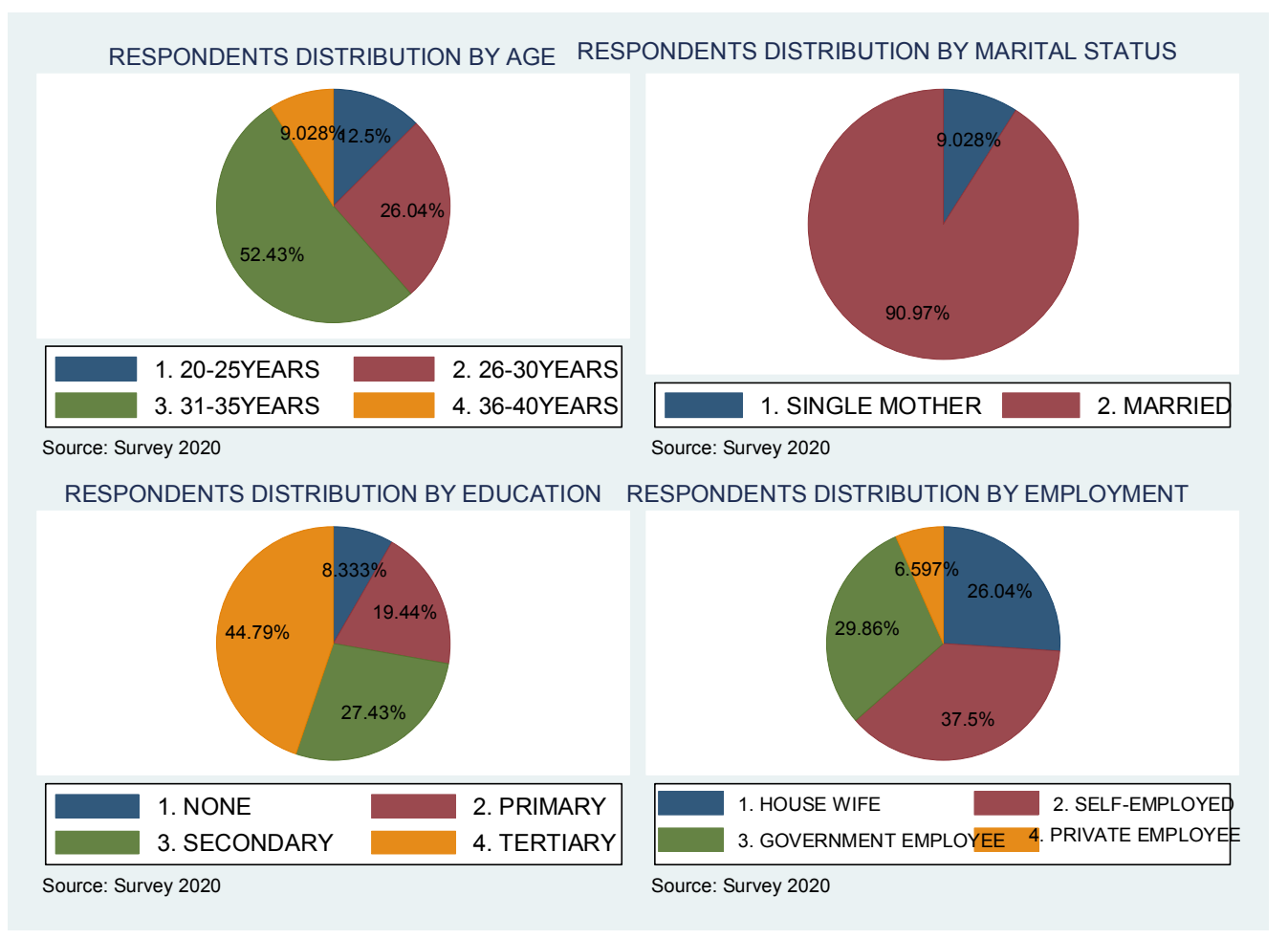

Figure 1. Socio-demographic characteristics. 


\subsection{Mother and Antenatal}

The figure 2 shows respondents' number of Antenatal visit and Health talk topics at antenatal clinic. $2(0.69 \%)$ of the total respondents claimed to have attended antenatal only one time, $63(21.88 \%)$ attended 2 times, $121(42.01 \%)$ attended 3 times, 48 (16.67\%) attended antenatal 4 times, 51 (17.71\%) attended 5 times and $3(1.04 \%)$ of the respondents attended antenatal more than 5 times before delivery. Regarding, health talk topic at antenatal clinic, $97.57 \%$ of the respondents attested that nurses taught them about Exclusive Breast Feeding (EBF), 89.93\% learnt about the benefit of EBF. Barrier to Exclusive Breast Feeding (BEBF) and 82.64\% were taught the risk of giving water, formula or other supplements (Risk - NEBF) to babies before six months of age. Concerning mode of delivery, 228 (79.17\%) of the respondents claimed that, they deliver their babies through Normal Vaginal delivery, while $60(20.83 \%)$ delivered their babies through Caesarean Section (see figure 2).
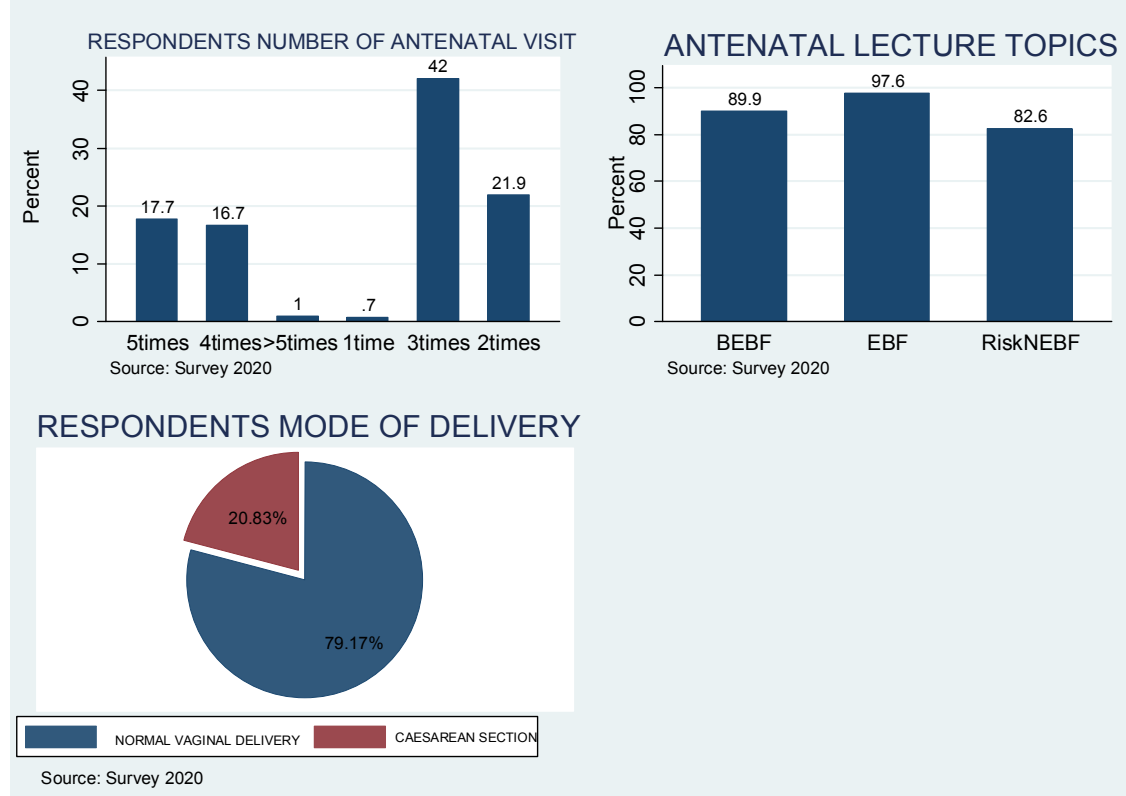

Figure 2. Antenatal experience and mode of delivery.

\subsection{Feeding Pattern}

Apropos to respondents feeding of their baby, $83.7 \%$ of the total respondents were Breast-feeding Exclusively (EBF), 4.9\% said they adopted both breastfeeding/feeding breast-milk substitutes (BOTH) method, 6.3\% preferred feeding my baby breast-milk substitutes while $4.5 \%$ were not breastfeeding at all (Not at) (see figure 3).

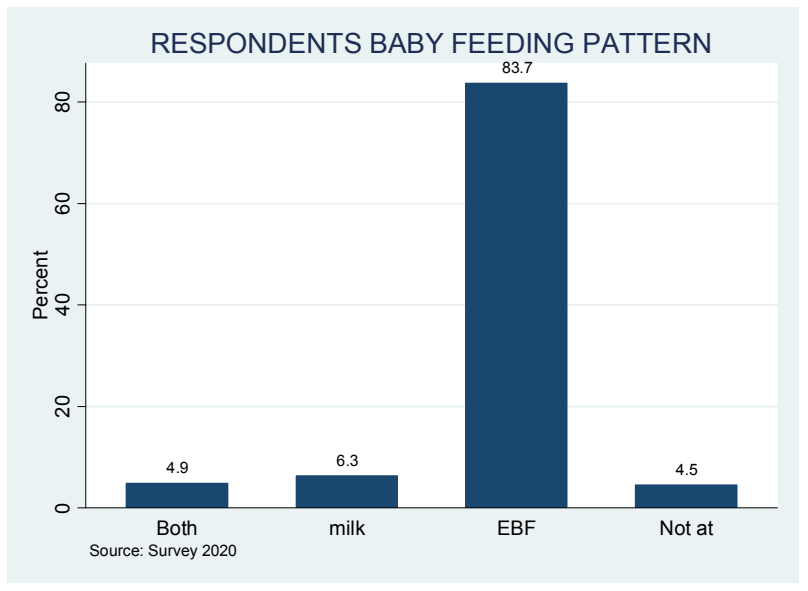

Figure 3. Feeding pattern.

\subsection{Attitude of Mother Toward Their New-born Babies}

The result of the attitude of mothers toward their new baby shows how mothers were bonded to their new-born babies. $122(43.6 \%)$ claimed that they held their babies immediately after birth, $72(25.7 \%)$ said within 5 minutes after birth, 55 (19.6\%) within 30 minutes, $9(3.2 \%)$ within 1 hour, $19(6.8 \%)$ admitted that as soon as they were able to respond after surgery for those who delivered through cesarean section, only $1 \%$ of the respondent can't remember when they first held their babies after delivery. The result also indicates, "how soon mothers initiate breastfeeding after birth," 98 $(36.43 \%)$ started immediately, $49 \quad(18.22 \%)$ initiated breastfeeding between 10 to 20 minutes, $22(8.2 \%)$ initiated it after 30 minutes, $4(1.5 \%)$ after 40 minutes, 5 (1.9\%) after 50 minutes, $16(5.5 \%)$ claimed to initiate breastfeeding after 1 hour of delivery while $9.7 \%$ of the respondent can't even remember when they did. Concerning how often respondents feed their babies, $10(3.5 \%)$ feed their babies every 10 minutes, 4 (1.4\%) feed every 20 minutes, 9 (3.2\%), feed every 30 minutes, 19 (6.7\%) feed every 1 hour, $232(82 \%)$ claimed to feed their babies on demand, $1(0.4 \%)$ feed anytime they have a chance while $8(2.8 \%)$ can't remember how often they feed their babies. Based on how long 
respondent intends to breastfeed their babies, $81(28.2 \%)$ respondents intended to breastfeed their babies for 3 months, $174(60.6 \%)$ desired to breastfeed for 6 months, $18(6.3 \%)$ intended 12 months, $10(3.5 \%)$ said 18 months, and $4(0.4 \%)$ of the total respondents planned to breastfeed for 24 months.

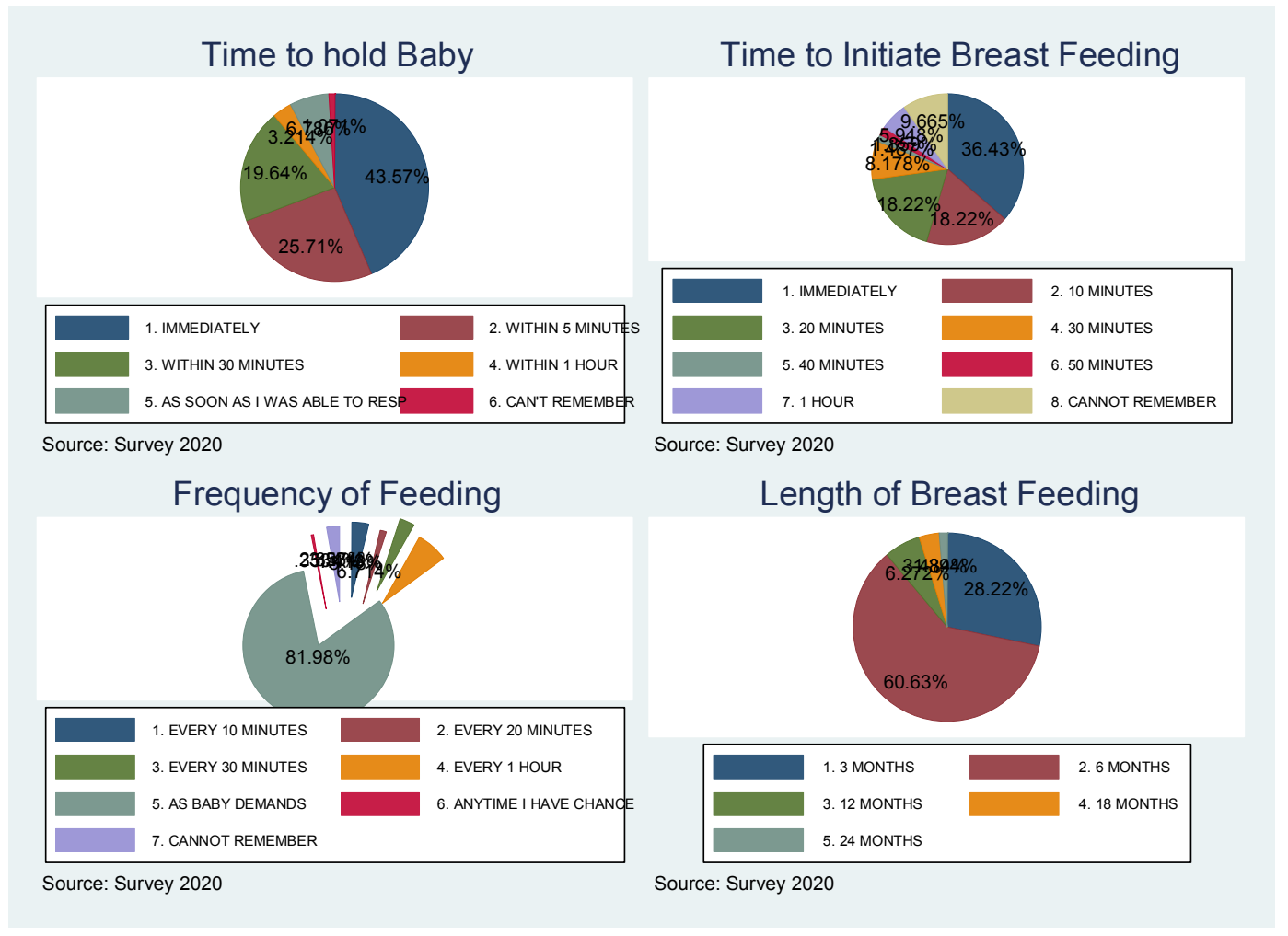

Figure 4. Attitude of Mother toward their New-born Babies.

Table 2. Attitude of Mother toward their New-born Babies.

\begin{tabular}{|c|c|c|}
\hline Variable & Frequency & Percentage (\%) \\
\hline \multicolumn{3}{|l|}{ Time to hold } \\
\hline Immediately & 122 & 43.6 \\
\hline Within 5 minutes & 72 & 25.7 \\
\hline Within 30 minutes & 55 & 19.6 \\
\hline Within 1 hour & 9 & 3.2 \\
\hline As soon Able & 16 & 6.8 \\
\hline Can't remember & 3 & 1 \\
\hline Total & 288 & 100.0 \\
\hline \multicolumn{3}{|c|}{ Time to initiate breast feeding } \\
\hline Immediately & 98 & 36.43 \\
\hline After 10 minutes & 49 & 18.22 \\
\hline After 20 minutes & 49 & 18.22 \\
\hline After 30 minutes & 22 & 8.2 \\
\hline After 40 minutes & 4 & 1.5 \\
\hline After 50 minutes & 5 & 1.9 \\
\hline After 1 hour & 16 & 5.55 \\
\hline Can't remember & 26 & 9.7 \\
\hline Total & 288 & 100.0 \\
\hline \multicolumn{3}{|l|}{ Frequency of feeding } \\
\hline Every 10 minutes & 10 & 3.5 \\
\hline Every 20 minutes & 4 & 1.4 \\
\hline Every 30 minutes & 9 & 3.2 \\
\hline Every 1 hour & 19 & 6.7 \\
\hline As baby demands & 232 & 82.0 \\
\hline Anytime I have chance & 1 & 0.4 \\
\hline Can't remember & 8 & 2.8 \\
\hline Total & 288 & 100.0 \\
\hline \multicolumn{3}{|l|}{ Length of breast feeding } \\
\hline 3 months & 81 & 28.2 \\
\hline
\end{tabular}

\begin{tabular}{lll}
\hline Variable & Frequency & Percentage (\%) \\
\hline 6 months & 174 & 60.6 \\
12 months & 18 & 6.3 \\
18 months & 10 & 3.5 \\
24 months & 4 & 0.4 \\
Total & 288 & 100.0 \\
\hline
\end{tabular}

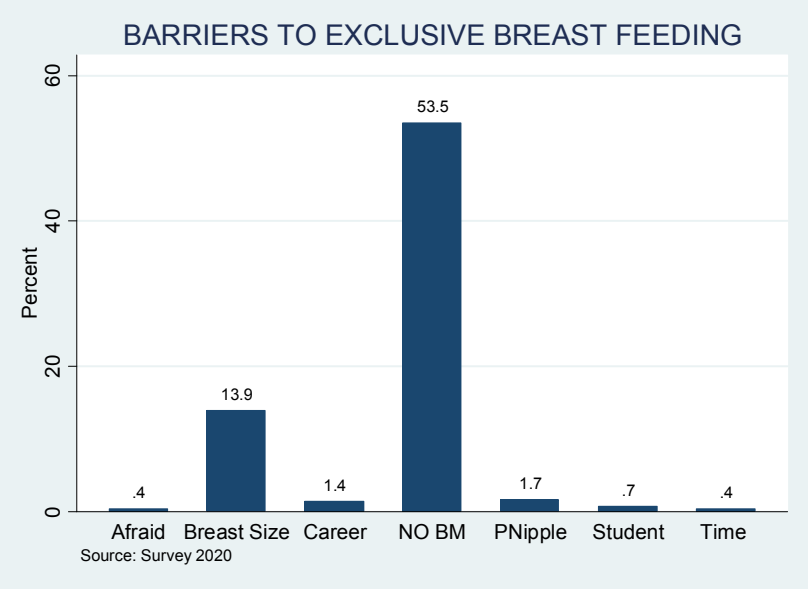

Figure 5. Barrier to exclusive breast feeding.

\subsection{Barriers Experiencing as It Regards Exclusive Breast Feeding}

The results of barriers experiencing by mother regarding 
Exclusive breastfeeding depicts that, $53.5 \%$ of the respondents contend with the challenge of not having enough breast milk, $13.9 \%$ think that the breast milk will not be enough for their babies because of the size of their breast, $0.69 \%$ have the challenge of being a student, the limitation of $1.4 \%$ of the respondent is being a career woman, $1.7 \%$ difficulty is painful nipples, only one person was afraid that the baby may refuse other food at a later age also, one respondent said it's time-consuming.

\subsection{Motivation}

Respondents' motivation based on whether, exclusive breastfeeding is beneficial to baby and mother shows that $99.6 \%$ of the respondent claimed that exclusive breastfeeding is beneficial, and contribute to good well-being of the baby, also $98.2 \%$ of respondents submitted that exclusive breastfeeding is beneficial to the nursing mother as well.

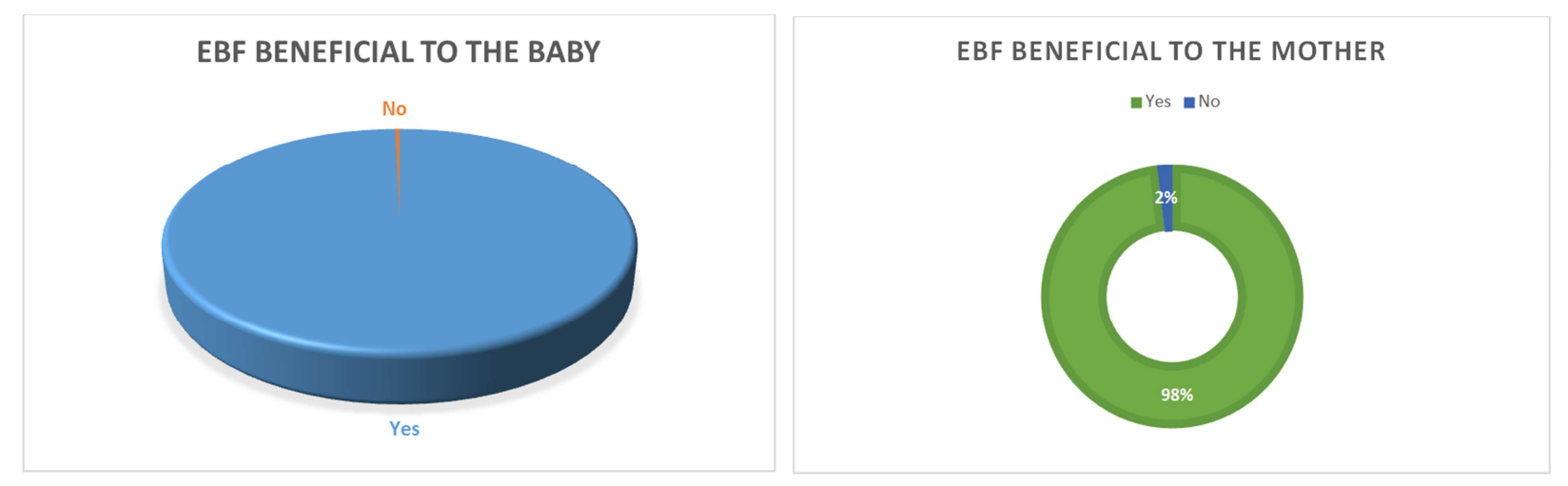

Figure 6. Motivation to breast feeding.

\section{Discussions}

Exclusive breastfeeding (EBF) is widely known to improve children's health, but poor breastfeeding rates are still reported in many developing countries, including Nigeria. This study shows that $53.5 \%$ of the respondents reportedly did not have enough breast milk, $13.9 \%$ think that the breast milk will not be enough for their babies because of the size of their breast, $0.69 \%$ have the challenge of being students whiles the limitation of $1.4 \%$ of the respondent is that they are career women. Only $1.7 \%$ complained of painful nipples; one person was afraid that the baby may refuse other food at a later age and one respondent said it's time-consuming.

The above maternal-baby factors such as the perceived insufficiency of milk have been reported previously as a key factor leading to early breastfeeding cessation [1. Redshaw M, Henderson J. Learning the hard way: Expectations and experiences of infant feeding support birth. 2012; 38 (1): 21 9] 2. Gatti L. Maternal perceptions of insufficient milk supply in breastfeeding. J Nurs Scholarsh. 2008; 40 (4): 355 63.]. As in other studies, perceived insufficient milk supply was the most commonly reported maternal-baby issue among our participants. Other authors such as Hector et al. Hector et al [32] maintain that only about $5 \%$ of women actually have physiological insufficient milk supply but up to $50 \%$ of mothers report to health facilities about insufficient milk for their baby. The motivation for breastfeeding is an important variable which should be considered, given that motivation is the agent propeller of all action [29].

Also, Hill \& Aldag explain this perception about the lack of breast milk results from doubting one's breastfeeding ability, which may lead to the perception of insufficient milk supply and adding other food, or fluids to the baby's diet [31].
Likewise, Justine A. Kavle et al. [30] agreed that poor latching and positioning perceived insufficient breast milk and breast engorgement are barriers to EBF. They also concluded from their findings that the providers often lacked the knowledge, skillset, and self-efficacy to manage EBF problems, with little counseling provided at community or facility levels. And discovered that, provision of job aid rollout, providers reported improved assessment of breastfeeding technique, and increased self-efficacy and motivation to identify and resolve EBF problems [24]. Other authors found related reasons such as EBF was very stressful $(26.2 \% ; n=67)$, mother's refusal $(23.5 \% ; n=60)$, EBF was not necessary $(18.1 \% ; n=46)$, time constraints, $35(13.7 \%)$ the husband's refusal accounted for $1.5 \%(\mathrm{n}=3)$ of the reasons for the non-practice of exclusive breastfeeding. (Ugboaja JO, Bertrand NO, Igwegbe AO, Obi-Nwosu AL).

Barriers to postnatal care and exclusive breastfeeding amongst urban women in south-eastern Nigeria. [25] Khasawneh, W. et. al found that besides multiparity, the main predictive factor for the success of EBF was the mother's own experience with EBF in her previous children. Also, Kitano N, Nomura K et. al, and Hackman N M et. al [26, 27, 33] further substantiates these findings which had claimed that it is not unexpected as most of the difficulties in breastfeeding are usually reported in young and nulliparous mothers, and these mothers need to be a target group with better education and support about the benefits, and techniques of breastfeeding to improve their future experiences.

\section{Conclusion}

The study has revealed some of the barriers to exclusive breastfeeding amongst mothers accessing care at the 
University of Abuja Teaching Hospital and its associated motivations. The hundred percent of success in exclusive breastfeeding requires full engagement and participation of the beneficiaries from the onset through to the implementation and effective monitoring of the program by consistently and continuous health information/education at all levels of care.

Also, the socio-demographic has an enormous factor in the barrier and the motivation of the exclusive breastfeeding by the respondents. It is also observed that another national program has overshadowed this important aspect of health among mothers, hence little or no attention is being given to EBF in other to support the SDG 3 and WHO assertions on this program at the University of Abuja Teaching Hospital Abuja

\section{Recommendations}

Based on the findings from this study, we recommend that:

1. The findings from this research become a step-wise strategy in effectively promoting WHO and UNICEF program at the University of Abuja Teaching Hospital, Gwagwalada

2. This has substantiated the reasons to effectively domesticate the program and ensure the goal of SDG 3 through efficient health education, and promotion as primary prevention at the Ante-Natal Clinic and National Program on Immunization at the University of Abuja Teaching Hospital, Gwagwalada

3. The study is expected to extend to other parts of the country where barriers are prominent and mothers can be motivated

4. A more advanced study using qualitative means to understand reasons for barrier amongst Mothers who are not practicing exclusive breastfeeding

5. Policymakers in Nigeria to assess closely these barriers and to design policies that can remedy and promote the increased practice

\section{Acknowledgements}

Our sincere appreciation goes to the participants of the study for their willingness to share their experiences and cooperation with the research assistant - Esther Ihotu Adams and many thanks to the Nurses/Midwives at the Post Natal Outpatient Clinic which is located at the Ante-Natal Clinic, the Community Health Extension Workers (CHEW) at the National Program on Immunization and all the members of the Global Health Network Club, University of Abuja Teaching Hospital, Gwagwalada.

\section{References}

[1] Baby-friendly Hospital Initiativehttps://www.who.int/nutrition/bfhi/en/

[2] You D, Hug L-Global, regional, and national levels and trends in under-5 mortality between 1990 and 2015, with scenariobased projections to 2030: a systematic analysis by the UN Inter-agency Group for Child Mortality Estimation.

[3] Semrau K, Kuhn L, Brooks RD, Cabral H, Sinkala M, et al. (2011) Exclusive breastfeeding, maternal HIV disease and the risk of clinical breast pathology in HIV-infected, breastfeeding women. Am J Obstet Gynecol 205

[4] Tamiru D, Belachew T, Loha E, Mohammed S (2012) Suboptimal breastfeeding of Infant during the first six months and associated factors in rural communities of Jimma Ario Woreda, Southwest Ethiopia. BMC Public Health 12: 363.

[5] Thakur S, Roy S, Pual K, Khannam M, Khatun W, et al. (2012) Effect of nutrition education on Exclusive breastfeeding for nutritional outcome of low birth weight babies Eur J ClinNutr 66: 376-381.

[6] Victoria CG, Bahl R, Barros AJ, FranÃ §a GV, Horton S, et al. (2016) Breastfeeding in the 21stcentury Epidemiology, mechanisms and lifelong effect. Lancet 387: 475-490.

[7] Horta BL, Victoria CG (2013) Short-term effects of breastfeeding: A systematic review of the benefits of breastfeeding on diarrhea and pneumonia mortality. WHO, Geneva.

[8] Bowatte G, Tham R, Allen KJ, Tan DJ, et al. (2015) Breastfeeding and childhood acute Otitis media: A systematic review and meta-analysis. ActaPaediatr 104: 85-95.

[9] Amitay EL, Keinan-Boker L (2015) Breastfeeding and childhood leukemia incidence: A meat- analysis and systematic review. JAMA Pediatr 169: e151025.

[10] Thophothai T, Thaijinda C, Seartgaikul N, Phuthasri V, Bunthumchareung K, et al. (2013). The study of perception of exclusive breastfeeding promotion and powdered Advertisement with knowledge, attitude and decision of mother and relative, Thailand.

[11] Peres KG, Cascaes AM, Nascimento GG, Victora CG (2015) Effect of breastfeedingonmalocclusions: A systematic review and meta-analysis. ActaPaediatr 104: 54-61.

[12] Stuebe AM, Schwarz EB (2010) The risks and benefits of infant feeding practices for women and their children. J Perinatol 30: 155-162.

[13] York E, Hoban E (2013) Infant feeding intentions among first time pregnant women in urban Melbourne, Australia. Midwifery 29: 787-793.

[14] Liu B, Jorm L, Banks E (2010) Parity, breastfeeding and the subsequent risk of maternal Type 2 diabetes. Diabetes Care 33: 1239-1241.

[15] Chowdhury R, Sinha B, Sankar MJ, Taneja S, Bhandari N, et al. (2015) Breastfeeding And maternal health outcomes: A systematic review and meta-analysis. ActaPÃ'diatr 104: 96113.

[16] Aune D, Norat T, Romundstad P, Vatten LJ (2014) Breastfeeding and the maternal Risk of Type 2 diabetes: A systematic review and dose-response meta-analysis of Cohortstudies Metab Cardiovasc Dis 24: 107-115.

[17] Dias CC, Figueiredo B (2015) Breastfeeding and depression: A systematic review of the literature. J Affect Disord 171: 142-154. 
[18] Bobrow KL, Quigley MA, Green J, Reeves GK, Beral V (2013) Persistent effects of women parity and breastfeeding patterns on their body mass index: Results from the million women study. Int J Obes 37: 712-717.

[19] Nualjam P, Phumthritikun P, Muttawangkul C, Kumrot W, Chuncha Chreun K, et al. (2013) Factors affected to behavior and during time for breastfeeding of Pasi Charoen person'sThailand.

[20] Kramer MS, Kakuma R (2012) Optimal duration of exclusive breastfeeding. Cochrane Database Syst Rev 8: CD003517.

[21] United Nations (2015) Transforming our world: The 2030 agenda for sustainable development, New York.

[22] WHO (2013) Exclusive breastfeeding.

[23] Kish, L. (1965): Survey Sampling. John Wiley \& Sons, Inc., New York, London 1965, IX + 643 S., 31 Abb., 56 Tab., Preis83 s.

[24] Kavle JA, Picolo M, Buccini G, Barros I, Dillaway CH, PérezEscamilla R (2019) Strengthening counseling on barriers to exclusive breastfeeding through use of job aids in Nampula, Mozambique. PLoS ONE 14 (12): e0224939. https://doi.org/10.1371/journal.pone.0224939

[25] Khasawneh, W., Khasawneh, A. A. Predictors and barriers to breastfeeding in north of Jordan: could we do better?Int Breastfeed J 12, 49 (2017) https://doi.org/10.1186/s13006017-0140-y

[26] Kitano N, Nomura K, Kido M, Murakami K, Ohkubo T, Ueno $\mathrm{M}$, et al. Combined effects of maternal age and parity on successful initiation of exclusive breastfeeding. Prev Med Rep. 2016; 3: 121-6. Available from: http://www.ncbi.nlm.nih.gov/pubmed/26844198

[27] Hackman NM, Schaefer EW, Beiler JS, Rose CM, Paul IM. Breastfeeding outcome comparison by parity. Breastfeed Med. 2015; 10: 156-62. Available from: http://www.ncbi.nlm.nih.gov/pubmed/25549051

[28] EditePintoa, Claudia Chavesa, Joao Duartea, Paula Nelasa\& Emilia Coutinhoa. Procedia-Social and Behavioral Sciences 217 (2016) 1028 - 10351033

[29] Baptista H. G., Gonçalves A. A.; G., Ruiz S. (2009). Factoresassociados à duração do aleitamentomaternoemcrianças - CadernoSaúdePública, Rio de Janeiro, 25 (3): 596-604, mar.

[30] JustineKavle, Megan L. Andry Megan Landry. Addressing barriers to maternal nutrition in low - and middle - income countries: A review of the evidence and programme implications August 2017 Maternal and Child Nutrition 14 (2) DOI: $10.1111 / \mathrm{mcn} .12508$

[31] Hill PD, Aldag J. Maternal perceived quality of life following childbirth. J Obstet Gynecol Neonatal Nurs. 2007; 36 (4): 328-34.

[32] Hector D, King L, Webb K, Heywood P. Factors affecting breastfeeding practices: applying a conceptual framework. $\mathrm{N}$ S W Public Health Bull. 2005; 16 (3-4): 52-5.

[33] Niger Med J. 2013 Jan; 54 (1) 45-50. DOI: 10.4103/03001652.108895. PMID: 23661899; PMCID: PMC3644744. 